\title{
An unexpected case of a difficult airway secured using an aintree intubating catheter for intermittent oxygenation and exchange of a laryngeal mask airway for an endotracheal tube
}

\author{
Jaime Ortiz ${ }^{*}$, Tameka M. Broussard ${ }^{2}$ and Ashutosh Wali ${ }^{1}$ \\ *Correspondence: jaimeo@bcm.edu \\ 'Department of Anesthesiology, Baylor College of Medicine, 1709 Dryden Road, Suite 1700, USA. \\ ${ }^{2}$ Greater Houston Anesthesiology.
}

\begin{abstract}
Failed endotracheal intubation will always be a major concern for anesthesiologists because of the devastating outcomes associated with it. Any methods used to safely secure a difficult airway ultimately improves patient outcome, prevents adverse events, and should be shared with others. The American Society of Anesthesiologists' difficult airway algorithm outlines multiple interventions that can be utilized to manage and secure a difficult airway. This report describes the integration of more than one technique to safely secure an airway. We present a 50 year-old, $74 \mathrm{~kg}$ male who presented for right ulnar nerve transposition and turned out to have a difficult airway. We describe how we emergently secured the airway successfully by using an Aintree intubating catheter as means of intermittent ventilation and for the exchange of an endotracheal tube via the laryngeal mask airway using the flexible fiberoptic bronchoscopy.
\end{abstract}

Keywords: Difficult airway, endotracheal intubation, laryngeal mask airway, aintree intubating catheter

\section{Introduction}

Despite advances in methods of endotracheal intubation, the availability of a wide variety of options for securing the airway, and the American Society of Anesthesiologists' practice guidelines for airway management, failed endotracheal intubation remains a significant clinical concern. There are suggestive data that findings obtained from a preoperative airway examination may have some correlation with the presence of a difficult airway. However, the current available means of preoperative airway assessment have only modest sensitivity and specificity [1]. Adverse outcomes following failed endotracheal intubations are amongst the most common anesthesia related events in the closed claims analysis. These outcomes include, but are not limited to death, brain injury, cardiopulmonary arrest, unnecessary tracheostomy, airway trauma, and damage to teeth [1].

\section{Case description}

A 50 year old male was scheduled for ambulatory day surgery for right elbow ulnar nerve transposition for right cubital tunnel syndrome. The patient reported several months of right small finger and ring finger pain as well as atrophy of the intrinsic muscles of the right hand. He had a BMI of 26.2 and his past medical history was significant for hypertension, type II diabetes mellitus, and hyperlipidemia. He had previous surgery, one month prior, with no complications. Airway examination revealed a Mallampati II airway, full range of motion of his neck, adequate mouth opening, and a thyromental distance of 3 finger breadths.
Upon arrival in the operating room, standard monitors were placed and the patient was pre-oxygenated with $100 \%$ oxygen for approximately 5 to 6 minutes. Anesthesia was induced with propofol $200 \mathrm{mg}$ IV and the ability to adequately mask ventilate was confirmed, but required two-hand technique. Succinylcholine $140 \mathrm{mg}$ was administered IV to facilitate endotracheal intubation. Direct laryngoscopy with a Macintosh size 3 revealed a Grade IV laryngoscopic view. A Bougie tracheal tube introducer (Smith Medical, Dublin, $\mathrm{OH}$ ) was easily passed through the cords. However, several attempts to pass an 8.0 ETT over the Bougie were unsuccessful. We removed the stylet in order to be able to ventilate the patient, at which time, ventilation became more difficult. At this time, a laryngeal mask airway size \#4 was easily placed and helped assist with ventilation. The oxygen saturation stayed above the high 80's throughout the episode.

Due to the patient's history of long standing diabetes and risk of aspiration, the decision was made to secure a more definitive airway. We placed the endotracheal tube utilizing the laryngeal mask airway, Aintree intubating catheter (Cook Medical, Bloomington, IN) and fiberoptic bronchoscope using the following steps:

1. The fiberoptic bronchoscope was passed through the Aintree catheter leaving $3 \mathrm{~cm}$ of the tip of the bronchoscope exposed.

2. The fiberoptic bronchoscope/Aintree catheter assembly was passed through the LMA into the trachea under visual guidance. 
3. The fiberoptic bronchoscope was removed. The Rapid-fit adapter (Cook Medical, Bloomington, IN) was connected to the Aintree catheter which allowed for ventilation. Ventilation was continued as the marking on the Aintree catheter relative to the patient's lips was noted.

4. The laryngeal mask airway was deflated and carefully removed over the Aintree catheter. The position of the Aintree was rechecked.

5. The tracheal tube was passed over the Aintree catheter into the trachea. The Aintree catheter was removed leaving the tracheal tube in place.

We re-confirmed the location of the endotracheal tube, above the carina, using the fiberoptic scope and the tube was secured. The rest of the patient's anesthetic and surgical procedure proceeded uneventfully and the patient was extubated at the end of the case without difficulty. As per our department's practice, we gave the patient a difficult airway letter to keep for any future anesthetics he may receive and explained the difficulty we experienced securing his airway.

\section{Discussion}

Difficult airway management can have a tremendous impact on patient outcome as well as the anesthesia care team. The American Society of Anesthesiologists' closed claims project database demonstrates that difficult endotracheal intubation is the second most frequent primary damaging event [2]. The severity of the outcomes can be devastating such as pulmonary aspiration, airway injury, brain damage, and even death. An ideal technique to achieve endotracheal intubation when conventional methods have failed should include:

1. An upper airway, preferable supraglottic, device that maintain airway patency and allows for adequate ventilation and oxygenation.

2. Facilitation of successful endotracheal intubation.

3. Uses universal skills that are easily learnt.

4. Allows direct visualization to pass a device into the trachea [3].

Passing an Aintree intubating catheter, preloaded on a fiberoptic scope, through an LMA for direct visualization of the cords and eventual railroading of a tracheal tube over the Aintree satisfies all these criteria.

Most failed intubation guidelines include recourse to an LMA due to its ability to maintain airway patency, gas exchange, universal skill possession, and widespread availability [3]. The Aintree intubating catheter is a $56 \mathrm{~cm}$ long, disposable hollow ventilation/exchange catheter with an internal diameter of $4.7 \mathrm{~mm}$, with a graduated scale (in $\mathrm{cm}$ ) along the outside. It can accommodate a Rapid-Fit $22 \mathrm{~mm}$ connector that allows for positive pressure ventilation. The Aintree catheter allows a fiber optic bronchoscope $4.0 \mathrm{~mm}$ or smaller to pass through leaving $3 \mathrm{~cm}$ of its tip unsheathed [1]. This technique is unique in that ventilation is uninterrupted throughout the sequence from rescue LMA maintenance until the trachea has been intubated [4]. We conclude that flexible fiberoptic intubation through an LMA using an Aintree catheter is an excellent method for management of the unexpected difficult airway.

\section{Competing interests}

The authors declare that they have no competing interests.

\section{Authors' contribution}

Drs. Ortiz, Broussard, and Wali were involved in the drafting of the manuscript, revision, and review of the final submission.

Publication history

Received: 5-Jan-2013 Accepted: 7-Jan-2013

Published: 17-Jan-2013

\section{References}

1. Practice guidelines for management of the difficult airway: an updated report by the American Society of Anesthesiologists Task Force on Management of the Difficult Airway. Anesthesiology 2003, 98:1269-77. | Article I PubMed

2. Miller CG: Management of the difficult intubation in closed malpractice claims. ASA Newsletter 2000, 64: 13-19. | Pdf

3. Higgs $A$, Clark E, Premaj K: Low-skill fiberoptic intubation: use of the aintree catheter with classic LMA. Anaesthesia 2005, 60: 915-920. | Article

4. Zura A, Doyle DJ and Orlandi M: Use of the Aintree intubation catheter in a patient with an unexpected difficult airway. Can J Anaesth 2005, 52:646-9. | Article | PubMed

\section{Citation:}

Ortiz J, Broussard T M and Wali A: An unexpected case of a difficult airway secured using an aintree intubating catheter for intermittent oxygenation and exchange of a laryngeal mask airway for an endotracheal tube. journal of Anesthesiology and Clinical Science 2013, 2:4.

http://dx.doi.org/10.7243/2049-9752-2-4 